\title{
IMPLICAÇÕES DO CAPITALISMO E A CRISE AMBIENTAL
}

Jacqueline Roberta Tamashiro, Munir Jorge Felício

Universidade do Oeste Paulista - UNOESTE, Mestrado em Meio Ambiente e Desenvolvimento Regional, Presidente Prudente, SP. E-mail: arquiteta.jtamashiro@hotmail.com

\section{RESUMO}

O presente artigo tem como objetivo a contribuição e discussão sobre quais as relações que existem entre o capitalismo e algumas das consequências vistas atualmente sob o âmbito ambiental. Em primeiro momento, demonstra um breve histórico sobre o desenvolvimento da produção capitalista e como isto está engendrado à insustentável extração de recursos naturais. Na segunda parte, o texto aborda algumas das interferências danosas observadas atualmente, como consequência de atividades iniciais do período da Revolução Industrial. O texto aborda algumas das crises enfrentadas na contemporaneidade, como a exploração voraz dos recursos hídricos; o uso intenso de praguicidas e herbicidas como forma de controle às pragas, e a crescente geração de resíduos sólidos urbanos. Por fim, são realizadas algumas considerações sobre a temática, elencando alternativas que sejam capazes de contribuir positivamente, conscientemente e racionalmente sobre o assunto.

Palavras-chave: Capitalismo. Crise ambiental. Recursos naturais.

\section{IMPLICATIONS OF CAPITALISM AND THE ENVIRONMENTAL CRISIS}

\begin{abstract}
The present paper aims at a contribution and discussion on which relations exist between capitalism and some of the consequences. First, it shows a brief history of the development of capitalist production and how it's engendered for unsustainable extraction of natural resources. In the second part, the text addresses some of the interferences observed, as a consequence of the activities of the period of the Industrial Revolution. The text addresses some of the crises in contemporary times, such as a voracious exploitation of water resources; the intensive use of pesticides and herbicides as a form of pest control, and a growing generation of urban solid waste. Finally, some considerations are made on the subject, alternative alternatives that help to contribute positively, consciously and rationally on the contract.
\end{abstract}

Keywords: Capitalism. Environmental crisis. Natural resources.

\section{INTRODUÇÃO}

Atualmente, a natureza, de forma geral, se encontra em constante processo de modificação. Modificação ou modificar, que vem do latim modificatio, significa mudar ou transformar algo, dar um novo modo de existência a uma substância material. No atual estado em que a encontramos, será que seria o mais correto chamarmos esse processo de modificação, alteração, transformação ou destruição?

Os cientistas reconhecem que a Terra é um sistema autorregulador composto de todas as suas formas vivas, incluindo os seres humanos e todas as partes materiais que a constituem. $\mathrm{O}$ sistema da Terra regula seu clima e sua química, visto que se assemelha a um organismo vivo e reage a tudo que fazemos (LOVELOCK, 2006). Assim sendo, a Terra não é algo inanimado; pelo contrário, é viva e em constante transformação natural (SILVA e CRISPIM, 2011). Porém, essa transformação natural referida pelo autor nos remete a um pensamento quase que cíclico e próprio da vida dos seres vivos. Logo, perante esta percepção ecológica, cabe-nos reconhecer que somos interdependentes de todos os fenômenos que acontecem, além do fato de que, enquanto indivíduos e sociedade, estaremos sim, encaixados dentro de todos os processos cíclicos 
da natureza, sendo dependentes destes processos (CAPRA, 1996).

As próprias atividades de sobrevivência do homem - principal beneficiário dos componentes oferecidos pelo mundo natural - já são vistas como uma interferência negativa sobre o meio ao qual vivemos. No entanto, é mais que necessário compreender que a natureza é finita de recursos, ou seja, uma fonte que pode vir a se tornar escassa. Capra (1996, p.14):

Defrontamo-nos com toda uma série de problemas globais que estão danificando a biosfera e a vida humana de uma maneira alarmante, e que pode logo se tornar irreversível [...] Quanto mais estudamos os principais problemas de nossa época, mais somos levados a perceber que eles não podem ser entendidos isoladamente [...] (CAPRA, 1996, p.14).

\section{METODOLOGIA}

Este trabalho foi elaborado a partir da metodologia denominada de estado da arte ou estado do conhecimento. A composição dos compêndios, aqui apresentados, fazem referência a elementos documentados sobre o assunto abordado. Envolveu a pesquisa documental e bibliográfica que pudesse trazer contribuições pertinentes ao assunto, expondo ainda à reflexão e relacionando diretamente com a temática sobre meio ambiente e capitalismo. As buscas foram realizadas em plataformas eletrônicas de periódicos científicos correspondentes à CAPES/MEC, Scientific Electronic Library Online (SCIELO) e ainda, em literatura que abordasse sobre o dano antropoceno causado ao meio ambiente. Os termos utilizados para compor 0 trabalho se definem em meio ambiente; capitalismo; consumismo e exploração de recursos naturais, no período (às reflexões precursoras) de 1985 a 2016.

\section{O capitalismo e a crise ambiental}

A Revolução Industrial, que teve início na Inglaterra durante o século XVIII, foi um marco importante no desenvolvimento mercantil. Como consequência da Revolução Industrial, a sociedade experimenta a impulsão do crescimento econômico, perspectivas de uma mudança na qualidade de vida e bem estar social. No entanto, paralelamente aos milagres oferecidos pelo rápido desenvolvimento, vieram os impactos ao meio ambiente, onde se observa quando passou-se a observar a intensificação de crises e problemas ambientais. No entanto, a acumulação de capital das grandes indústrias ainda era alimentada pelo trabalho camponês de pequenos agricultores e suas plantações (LUXEMBURG, 1985). Assim, a como consequência do crescimento socioeconômico, observa-se a necessidade da ampliação de centros urbanos. Silva e Crispim (2011, p.165):

Vários problemas
ambientais vieram com a
urbanização tais como:
concentração
populacional; consumo
excessivo de recursos
renováveis e não
renováveis; contaminação
das águas, solo e ar;
desmatamentos, entre
outros (SILVA e CRISPIM,
2011, p.165).

Esta urbanização em expansão acelerada foi um dos subprodutos mais relevantes da Revolução Industrial. "Por volta de 1850, havia mais cidadãos britânicos morando em cidades do que no campo, e quase um terço da população total vivia em cidades com mais de 50.000 habitantes" (SILVA e CRISPIM, 2011, p.165). Como resultado, um novo cenário abrangia as grandes cidades, as quais eram "cobertas de fumaça e impregnadas de imundice". Aspectos de saneamento e infraestrutura, como o abastecimento e a distribuição de água, os esgotos sanitários e os espaços abertos, não acompanhavam a migração de pessoas (DIAS apud SILVA e CRISPIM, 2011). Completa Felício (2013, p.188):

A questão econômica gerada com o avanço do capitalismo que se desenvolve sobre duas bases fundamentais - o processo de urbanização e de industrialização - e que se expande cada vez saqueando os recursos naturais e, avançando sobre a riqueza dos ecossistemas para convertê-los em valor de troca e coisificar o mundo 
e fetichizando as relações sociais (FELíCIO, 2013, p.188).

Juntamente a essa premissa, vieram acompanhados o uso massivo de energia e o consumo desenfreado de recursos naturais. Segundo Leff (2000, p.312), "a ciência e a tecnologia se converteram na maior força produtiva e destrutiva da humanidade". Neste período, os recursos ainda eram tidos como fontes inesgotáveis. Durante o século $X X, a$ sociedade se mobiliza pela primeira vez em busca de uma nova gestão e novas políticas para o uso de alguns recursos naturais, como a água, as florestas e os minérios (SILVA e CRISPIM, 2011). A partir dos anos 50, surgem indícios dos efeitos da crise ambiental. O almejo pela conservação ambiental se tornaria cada vez mais integrado; "com isso criou-se uma configuração territorial que foi cada vez mais o resultado de uma produção histórica e tende a uma negação da chamada natureza natural, substituindo-a por uma natureza inteiramente humanizada" (SILVA e CRISPIM, 2011).

Por fim, Silva e Crispim (2011) ressaltam que os problemas ambientais se tornaram ainda mais intensos pela própria ação consequente de ininterruptas atividades industriais. Verifica-se, neste período, elevadas taxas de emissões de gases poluentes e substâncias tóxicas nocivas no ar. Em longos períodos, o capitalismo deixou transparecer o fato de se "especializar" em seu papel, como no século XIX, quando se "deslocou de modo espetacular voltado ao novo mundo da indústria". Essa especialização levou o capitalismo a mostrar sua verdadeira identidade, com a "explosão da mecanização e seus maquinários; indivisibilidade de interesses; concretude, rigidez, estreitamento ou até mesmo fechamento de opções, e consequentemente, estar sempre no alto comando da economia" (ARRIGHI, 2009, p.05).

\section{As interferências danosas e a situação atual da crise}

Em um contexto atual, a crise ambiental ainda é elencada a fatores econômicos, sociais e políticos. "Economistas eminentes alertaram, há mais de vinte anos, que esse processo conduziria a uma economia de baixo crescimento num futuro próximo" (CHOMSKY, 2010, p.26).

Como herança dos séculos passados, temos o reflexo do capitalismo em atividades exploratórias e consumo desenfreado aos recursos naturais, muitas vezes extrativistas, que resultaram na presente problemática da crise ambiental. Ao estudarmos os principais problemas que vêm acontecendo, somos levados a refletir e perceber que os mesmos não podem ser entendidos isoladamente. Tais problemas são de cunho sistêmico, ou seja, são interligados e interdependentes (CAPRA, 1996). A preocupação com a exploração de recursos hídricos; o uso contínuo de praguicidas e herbicidas; a crescente geração de resíduos sólidos, sem destinação apropriada, são alguns dos presentes dilemas que podemos perceber em dias atuais.

\section{A exploração dos recursos hídricos}

No contexto de desenvolvimento sustentável, destaca-se o carácter dual que adquire a água na sua relação com a sociedade: pode ser vista como um recurso natural ou um passivo ambiental. Recurso natural, pois é um agente indispensável para a manutenção do ciclo da vida, onde a exploração sem precedentes pode acarretar em um colapso social (NINA; SZLAFSZTEIN, 2015). A intensificação da exploração dos recursos hídricos se deu a partir da segunda metade do século $X X$, tornando os impactos cada vez mais severos e complexos. A diversificação do uso da água no desenvolvimento econômico e social - como provedora de saneamento em centros urbanos, subsídio para grandes produções agrícolas e fonte geradora de energia - produziu inúmeras pressões sobre o ciclo hidrológico e reservas de águas superficiais e subterrâneas. Como resultado, observa-se um grande conjunto de degradação e poluição, que ainda acompanham os dias atuais (TUNDISI, 2005).

Capra (1996) nos revela que fatos como a escassez de recursos naturais e a contínua degradação do meio ambiente estão interligadas à rápida expansão populacional. Entretanto, segundo Tundisi (2005), o consumo de água perante as atividades humanas varia muito entre diversas regiões e países. "Os vários usos múltiplos da água e as permanentes necessidades de água para fazer frente ao crescimento populacional e às demandas industriais e agrícolas têm gerado permanente pressão sobre os recursos hídricos superficiais e subterrâneos." (TUNDISI, 2005, p.27).

Ainda Tundisi (2005, p. XVII):

[...] Os usos múltiplos e excessivos e as retiradas 
permanentes para

diversas finalidades têm diminuído

consideravelmente a disponibilidade de água e produzido inúmeros problemas de escassez sem muitas regiões e países. [...] No limiar do século $X X I$, entre outras crises sérias, a crise da água é uma ameaça permanente à humanidade e à sobrevivência da biosfera como um todo. [...] ela impõe dificuldades ao desenvolvimento, aumenta a tendência a doenças de veiculação hídrica, produz estresses econômicos e sociais e aumenta as desigualdades entre regiões e países. A água sempre foi recurso estratégico à sociedade. $\mathrm{O}$ crescimento populacional e as demandas sobre os recursos hídricos superficiais e subterrâneos são algumas das causas fundamentais da crise (TUNDISI, 2005, p. XVII).

Silva e Crispim (2011) ressaltam que existem públicos exageradamente otimistas em relação à escassez iminente. Alguns afirmam que, seja no presente ou futuro, qualquer problema de escassez poderá ser solucionado com a possibilidade de substituição de insumos ou matérias-primas e até mesmo no processo de produção. Silva e Crispim (2011, p.166):

Diante da possibilidade de esgotamento de certos recursos naturais, o preço de mercado aumentaria, forçando a ciência a pesquisar e aproveitar melhor o recurso escasso e encontrar alternativas para substituí-lo. Esta visão chamada de cornucopiana $^{1}$ considera todos os recursos infindáveis e diante da

${ }^{1} \mathrm{~A}$ abordagem cornucopiana tem origem teórica no "tecnocentrismo" sustentado na racionalidade econômica e eficiência tecnológica (SACHS, 2008). eminente escassez sempre será encontrado algum substituto (SILVA e CRISPIM, 2011, p.166).

Esta ideia quase que visionária, na qual o homem usa a natureza como valor de troca ou capital natural para superar a escassez física e biológica através de ajustes tecnológicos, pode ser refutada, em contrapartida, com a abordagem de Lovelock (2006, p.20) "por meio de um entendimento do anormal, delineamos, como uma silhueta recortada numa folha de papel, o estado de saúde normal, que é muito mais incompreensível". Confirma Tundisi (2005, p.02):

\begin{abstract}
Amplia-se a percepção de que a água é um recurso finito, de que limites em seu uso e os custos de tratamento estão cada vez mais elevados, além disso os custos da recuperação de lagos, rios e represas são também muito altos (TUNDISI, 2005, p.02).
\end{abstract}

As avaliações sobre a água, perante sua disponibilidade no planeta e seu papel no desenvolvimento, estão mostrando, cada vez mais, a necessidade de mudanças substanciais na direção do planejamento e gerenciamento dos recursos hídricos, ou seja, as águas superficiais e subterrâneas (TUNDISI, 2005).

\section{Praguicidas e herbicidas, os fins justificam os meios?}

Carson (2013) afirma que o uso de substâncias tóxicas, como herbicidas e praguicidas, tiveram seu início de utilização de forma sorrateira, sobre plantações e campos. Porém, naquele período, ainda havia o cuidado para que o veneno não encontrasse mais nada além do alvo. Com o desenvolvimento de novos inseticidas orgânicos e a abundância de aviões após a Segunda Guerra Mundial, o uso se tornou indiscriminado. Logo, não eram apenas as florestas e campos cultivados que respiravam a nuvem tóxica, mas também os vilarejos e as cidades.

"O grande uso de inseticidas, herbicidas, fertilizantes, implementos e outros produtos industrializados fizeram com que a agricultura se tornasse uma atividade intensiva e degradante do meio ambiente" (SILVA e CRISPIM, 2011, 
p.165). Porém, ao longo dos anos, as pulverizações em massa com outros tóxicos sobre grandes áreas se tornaram corriqueiras. A explicação paradoxal dada por usuários é a de que "os fins justificam os meios" (CARSON, 2013, p.138). Quando o assunto em pauta é a degradação ambiental, os argumentos empresariais incluem apenas 0 comprometimento com a lucratividade e competitividade, com estratégia de externalizar os custos ambientais, transferindo-os todos para a sociedade, poupando o verdadeiro causador, as grandes indústrias e outros potenciais do capitalismo (SILVA e CRISPIM, 2011).

Diferentemente seria se observássemos o procedimento de alguns silvicultores que, como fator de proteção, tomam o cuidado de inocular as novas florestas com a biodiversidade do local. Os próprios agentes da natureza se encarregam de executar o controle de pragas sem o uso de praguicidas. São aves, insetos predadores de pragas e as próprias bactérias do solo (CARSON, 2013).

"Estamos acostumados a procurar os efeitos flagrantes e imediatos e a ignorar tudo o mais. A não ser que o efeito apareça de pronto e de forma tão óbvia que não possa ser ignorado, negamos a existência do risco" (CARSON, 2013, p.164).

\section{O consumismo e seus resíduos}

O aumento da poluição, causada pelo depósito e descarte irregular de rejeitos, tem seu início logo após o período da Revolução Industrial. Os resíduos passam a compor um volume crescente de rejeitos gerados pela diversidade de substâncias e materiais processados, diferentemente do que se encontrava anteriormente como bem natural (SILVA e CRISPIM, 2011). Esta concentração espacial, proveniente do aumento crescente da geração dos resíduos, dificulta a assimilação realizada pelo próprio meio ambiente e altera a paisagem natural com impactos negativos. Elementos essenciais como a qualidade da água, do solo e do ar, em geral, do meio físico, são diretamente afetados por altos níveis de contaminação (ZANTA et al, 2006). Já Silva e Crispim (2011, p.164-165) abordam a correlação entre o consumismo e a geração de resíduos:

Os problemas ambientais de ordem antrópica decorrem do uso do meio ambiente para obter os recursos necessários para produzir bens e serviços, proporcionando conforto ao ser humano. $O$ que $O$ homem "acha" (considera) que não serve mais é descartado no ambiente; mas isso nem sempre gerou degradação ambiental, em razão da escala reduzida de produção e consumo e da maneira pela qual os seres humanos entendiam sua relação com a natureza e interagiam com ela. A sociedade consumista em que vivemos enfrenta a acelerada degradação dos recursos naturais que compromete a qualidade de vida, principalmente das futuras gerações e, por outro lado, leva nossa sociedade a procurar modelos alternativos que harmonizem o desenvolvimento econômico com a indispensável proteção ambiental (SILVA e CRISPIM, 2011, p.164165).

Silva e Crispim (2011, p.165) ainda ressaltam que "o aumento da escala de produção de bens de consumo têm sido um importante fator que estimula a exploração dos recursos naturais e eleva a quantidade de resíduos". Estes resíduos sólidos apresentam diversidade e complexidade em sua composição. As características físicas, químicas e biológicas variam de acordo com a proveniência de sua fonte geradora. Completam Zanta et al. (2006, p.02):

O conhecimento das características e da classificação dos resíduos sólidos é um dos subsídios para o prognóstico de estratégias de gerenciamento de resíduos. $O$ gerenciamento adequado minimiza possíveis impactos ambientais e prejuízos à saúde pública decorrentes da liberação de emissões 


$\begin{array}{lr}\text { gasosas e } & \text { líquidas } \\ \text { associadas } & \text { às } \\ \text { características } & \text { dos }\end{array}$

resíduos sólidos (ZANTA et al., 2006, p.02).

A boa qualidade do meio ambiente é uma das mais importantes preocupações da sociedade moderna. $O$ elemento que motiva essa priorização é o impacto do desenvolvimento tecnológico aumentando as mudanças no estilo de vida do homem (SILVA e CRISPIM, 2011). Porém, Leff (2000) aborda que se deve investigar e se orientar pelas formações de políticas ambientais e de desenvolvimento sustentável, e buscar compreender quais os efeitos das políticas econômicas atuais sobre a dinâmica dos ecossistemas.

\section{CONSIDERAÇÕES FINAIS}

Diante do histórico apresentado no texto, podemos perceber que as atividades capitalistas estão interligadas às decorrentes crises ambientais vistas atualmente. "Embora problemas ambientais perpassem semelhantemente por todos os países, porém com algumas especificidades. Os interesses em jogo são muito grandes na sociedade globalizada, visto que o lucro é a base do desenvolvimento" (SILVA e CRISPIM, 2011, p.173).

Desde os primórdios o ser humano já intervia na natureza, buscando por recursos naturais que oferecessem subsídios para seu sustento. Tais buscas eram feitas em pequenas escalas, das quais a própria natureza tratava de restituir. Entretanto, o ser humano também se desenvolve e se transforma; logo, o meio em que vive também sofre as interferências. A Revolução Industrial trouxe consigo a expansão da produção em larga escala de bens de consumo - a rapidez de fabricar em poucos minutos o que antes um artesão levava dias, ou até meses, para obter em uma única produção. Consequentemente, trouxe também hábitos de consumismo acelerado, uma característica que se segue até os dias atuais. Observa-se que a natureza e seus inúmeros atributos pertinentes não conseguem acompanhar as intervenções negativas das quais o homem vem engendrando.

Hoje, os recursos hídricos são explorados pela intensa diversificação de seus usos, visando alimentar o exclusivamente o desenvolvimento econômico. Enquanto alternativas não são elencadas, a tecnologia por si só não provém um desenvolvimento ecoeficiente (TUNDISI, 2005). A forma indiscriminada que os praguicidas e herbicidas são pulverizados afetam não somente as plantações as quais se destinam, mas antes todo o bioma ao seu redor; o solo, o ar, os recursos hídricos até, finalmente, as frágeis vegetações. Isto mostra que, ainda assim, os fins não justificam os meios aos quais são utilizados (CARSON, 2013). E ainda, os resíduos, infelizmente, são uma realidade de todos os centros urbanos, uma vez que o volume descartado acompanha a velocidade do consumismo. Consumismo que está impregnado à cultura e a natureza por si só, não consegue processar naturalmente a diversidade de materiais e substâncias (CHOMSKY, 2010; SILVA e CRISPIM, 2011).

Hoje, o conceito de desenvolvimento sustentável nos acrescenta uma outra dimensão a ser revista proficuamente: a dimensão da sustentabilidade social, que nos compele a trabalhar com escalas de tempo, ciência e espaço, buscando sempre por soluções que "eliminem o crescimento selvagem obtido ao custo de elevadas externalidades negativas, tanto sociais como ambientais" (SACHS, 2008, p.15). As estratégias devem ser permanentemente revisadas e deve-se eliminar medidas de cunho instantâneo, tomadas a curto prazo, que visam somente remediar as presentes crises ambientais. Estas levam ao crescimento destrutivo, mas socialmente benéfico, ou ao crescimento ambientalmente benéfico, mas socialmente destrutivo (SACHS, 2008). Por conseguinte, Capra (1996, p.15):

Há soluções para os principais problemas de nosso tempo, algumas delas até mesmo simples. Mas requerem uma mudança radical em nossas percepções, no nosso pensamento e nos nossos valores. E, de fato, estamos agora no princípio dessa mudança fundamental de visão do mundo na ciência e na sociedade, uma mudança de paradigma tão radical como o foi a revolução copernicana. Porém, essa compreensão ainda não despontou entre a maioria dos nossos líderes políticos. 
reconhecimento de que é necessária uma profunda mudança de percepção e de pensamento para garantir a nossa sobrevivência (CAPRA, 1996, p.15).

Sachs (2008) ainda ressalta que as estratégias a serem modificadas são as de políticas públicas, que possuem fortes funções sobre o desenvolvimento sustentável. Uma das funções citadas é o poder do Estado de articular espaços de desenvolvimento desde o nível local, onde deve ter base e fortalecimento ampliado e estratégia cautelosa de integração seletiva que atue de forma endógena, e não o contrário. Uma segunda função seria a de promover parcerias com todos os agentes interessados, firmando acordos a fim de vislumbrar um desenvolvimento realmente sustentável. Uma última função seria a harmonização no alcance de metas em comum, tanto no âmbito social, como no econômico e ambiental. Sendo assim, o Estado tem o poder de gerenciar o cotidiano da economia e da sociedade, buscando assim o equilíbrio entre diferentes potenciais de sustentabilidade e ecoeficiência, sejam sociais, culturais, ecológicas, ambientais, territoriais, econômicas e políticas (SACHS, 2008).

Morin (2010) completa que, "efetivamente, é o domínio do domínio da natureza que hoje nos causa problemas" (MORIN, 2010, p.36). De acordo com Chomsky (2010) muitos pessimistas poderão ir além e concluir que a sociedade está enredada neste sistema retrógrado, de domínios que prevalecem o subsídio pródigo de grandes empresas e trabalham para promover os interesses empresariais em numerosas frentes. Complementa Silva e Crispim (2011), que o problema da degradação ambiental tem amplitude necessária para mover os sentimentos de todos os habitantes deste planeta, pois é transacional. Ainda Felício (2013, p.203) enfatiza que:

Elencar alternativas
capazes de problematizar
e impulsionar o debate,
com a construção de uma
ciência com consciência e
estratégicas, mesmo que
utópicas capazes de matar
a morte engendrada pelo
veneno científico (FELÍ́cıO

apud MORIN, 2010, p.21). Deve-se desconstruir o pensamento fetichizado, para que o ser humano almeja algo, não aceitando pacificamente ser um componente de uma sociedade sem propósito, sem utopia, mas defender a hipótese de que uma outra sociedade é possível. A palavra final não está com o capital (FELÍCIO, 2013, p.203).

Entretanto, "é preciso elencar forças de um Estado enxuto, limpo, ativo, planejador e capaz de descortinar o futuro. Por enquanto, a cidadania global continua como uma utopia almejada" (SACHS, 2008, p.11). Este movimento de transformações positivas devem ser a "ética da libertação"; onde transformar é mudar o rumo de uma intenção, ou o conteúdo de uma norma, ou de uma ação. "Libertar significa não apenas quebrar as cadeias, mas também desenvolver a vida humana, exigindo-se que as instituições, o sistema, abram novos horizontes que transcendam a mera reprodução como repetição de o mesmo" (DUSSEL, 2000, p. 566).

Assim, estima-se que a essência deste estigma, da atual preocupação com o meio ambiente, não transmita o idealismo de um "puritanismo rabugento" (LOVELOCK, 2006). Não seria a crise atual parte de um acontecimento sistêmico? Acontecimento sistêmico que está interligado a todas intervenções realizadas até então? "Se formos capazes de pensar que somos parte de um organismo vivo gigantesco, e talvez até mesmo uma casa da sua indigestão, então poderemos ser guiados para viver em Gaia ${ }^{2}$ de uma maneira conveniente e saudável. Pensar assim é até mesmo um antídoto para o fatalismo de acreditar que a Terra é um planeta morto, sendo a vida apenas um passageiro" (LOVELOCK, 2006, p.20).

\section{AGRADECIMENTOS}

Agradecimentos à CAPES - Coordenação de Aperfeiçoamento de Pessoal de Nível Superior, pelo subsídio aos estudos, e ao NEAGEO - Núcleo de Estudos Ambientais e

\footnotetext{
${ }^{2}$ Gaia é o nome dado pelo autor à Terra, entendida como um sistema fisiológico, autorregulador e em evolução. (LOVELOCK, 2006, p.12)
} 
Geoprocessamento da Universidade do Oeste Paulista, UNOESTE.

Os autores declaram não haver qualquer potencial conflito de interesse que possa interferir na imparcialidade deste trabalho científico.

\section{REFERÊNCIAS}

ARRIGHI, G. O longo século XX. Dinheiro, poder e as origens de nosso tempo. 7. ed. Rio de Janeiro: Contraponto, 2009.

CAPRA, F. A teia da vida. Uma nova compreensão científica dos sistemas vivos. São Paulo: Cultrix, 1996.

CARSON, R. Primavera silenciosa. 3. ed. São Paulo: Gaia, 2013.

CHOMSKY, $N$. O lucro ou as pessoas? Neoliberalismo e ordem global. 6. ed. Rio de Janeiro: Bertrand Brasil, 2010.

DUSSEL, E. Ética da libertação na idade da globalização e da exclusão. Petrópolis: Vozes, 2000.

FELÍCIO, M.J. Apontamentos de epistemologia ambiental. Revista Geoambiente, Jataí-GO, n.21, jul./dez.p.184-204. 2013.

LEFF, E. Complexidade, interdisciplinaridade e saber ambiental. Interdisciplinaridade em ciências ambientais. São Paulo: Signus, 2000.

LOVELOCK, J. Gaia: Cura para um planeta doente. São Paulo: Cultrix, 2006.

LUXEMBURG, R. A acumulação do capital. São Paulo: Nova Cultural, 1985.

MORIN, E. Ciência com consciência. 13. ed. Rio de Janeiro: Bertrand Brasil, 2010.

NINA, A.S.; SZLAFSZTEIN, C.F. Água, recurso natural e passivo ambiental: relações entre a política nacional de recursos hídricos e a política nacional de proteção e defesa civil. In: SIMPÓSIO BRASILEIRO DE RECURSOS HÍDRICOS. 21., 2015, Brasília. Anais... Brasilia, 2015.

SACHS, I. Desenvolvimento includente, sustentável e sustentado. Rio de Janeiro: Garamond, 2008.

SILVA, V.B.; CRISPIM, J.Q. Um breve relato sobre a questão ambiental. Revista Geomae, Campo Mourão, v. 02, n. 01, , p.163-175. 2011

TUNDISI, J.G. Água no século XXI: Enfrentando a escassez. 2. ed. São Calos: Rima, 2005.

ZANTA, V.M. et al. Resíduos sólidos, saúde, e meio ambiente: Impactos associados aos lixiviados de aterro sanitário. 1.ed. Rio de Janeiro: ABES, 2006.
Recebido para publicação em 17/04/2017

Revisado em09/07/2017

Aceito em 04/08/2017 